\title{
Supraglottic Airway Devices
}

\author{
Satya Krishna Ramachandran MD FRCA and Anjana M Kumar
}

\author{
Classification of Supraglottic Airway Devices \\ Evolution of the Supraglottic Airway Device \\ Clinical Use of Supraglottic Airway Devices \\ Alternative to Tracheal Intubation for Routine Anesthesia \\ Tracheal Intubation Aide \\ Blind Tracheal Intubation Through Supraglottic Airway Devices \\ Fiberoptic-Guided Tracheal Intubation Through Supraglottic Airway \\ Devices \\ Rescue Airway: Difficult Intubation, Failed Intubation, Cannot \\ Intubate, and Cannot Ventilate \\ Resuscitation and Prehospital Airway Management \\ Tracheal Extubation Aide \\ Complications of Supraglottic Airway Devices \\ Ventilatory Failure \\ Airway Injury \\ Pulmonary Aspiration of Gastric Contents \\ Contraindications for Use of Supraglottic Airway Devices \\ Tips and Tricks for Successful Use of Supraglottic Airway Devices \\ Summary
}

\begin{abstract}
Supraglottic airway devices (SADs) are used to keep the upper airway open to provide unobstructed ventilation. Early (first-generation) SADs rapidly replaced endotracheal intubation and face masks in $>40 \%$ of general anesthesia cases due to their versatility and ease of use. Second-generation devices have further improved efficacy and utility by incorporating design changes. Individual second-generation SADs have allowed more dependable positive-pressure ventilation, are made of disposable materials, have integrated bite blocks, are better able to act as conduits for tracheal tube placement, and have reduced risk of pulmonary aspiration of gastric contents. SADs now provide successful rescue ventilation in $>\mathbf{9 0 \%}$ of patients in whom mask ventilation or tracheal intubation is found to be impossible. However, some concerns with these devices remain, including failing to adequately ventilate, causing airway damage, and increasing the likelihood of pulmonary aspiration of gastric contents. Careful patient selection and excellent technical skills are necessary for successful use of these devices. Key words: therapeutics; airway management; intubation; intratracheal; laryngeal masks [Respir Care 2014;59(6):920-932. (C) 2014 Daedalus Enterprises]
\end{abstract}

The authors are affiliated with the Department of Anesthesiology, University of Michigan, Ann Arbor, Michigan.

Dr Ramachandran presented a version of this paper at the 52nd RESPIRATORY CARE Journal Conference, "Adult Artificial Airways and Airway Adjuncts" held June 14 and 15, 2013, in St Petersburg, Florida.

This work was supported by the Department of Anesthesiology, University of Michigan. Dr. Ramachandran is a paid ad hoc consultant to
Galleon Pharmaceuticals and Merck. Ms Kumar has disclosed no conflicts of interest.

Correspondence: Satya Krishna Ramachandran MD FRCA, Department of Anesthesiology, University of Michigan Medical School, 1 H427, University Hospital Box 0048, 1500 East Medical Center Drive, Ann Arbor, MI 48109-0048. E-mail: rsatyak@med.umich.edu.

DOI: $10.4187 /$ respcare.02976 


\section{Supraglottic Airway Devices}

\section{Classification of Supraglottic Airway Devices}

Supraglottic airway devices (SADs) are devices that keep the upper airway clear for unobstructed ventilation. SADs have also been called supraglottic airways and extraglottic or periglottic airway devices. The laryngeal mask airway (LMA) refers to SADs produced by the manufacturers of the LMA Classic (LMA North America [San Diego]). The acronym LM refers to a laryngeal mask manufactured by anyone other than the original manufacturers. ${ }^{1}$ SADs can be classified based on 2 main distinctions. The first is the presence or absence of an inflatable cuff. Cuffless devices may provide reduced risk of cuff-related morbidity but may be associated with increased risk of leaks and failure. A more commonly employed classification is first-generation and second-generation SADs. First-generation de- vices are simple airway tubes that do not have specific design characteristics aimed at reducing the risk of pulmonary aspiration of gastric contents. Second-generation SADs incorporate specific features to improve positivepressure ventilation (PPV) and reduce the risk of aspiration. The design characteristics of various SADs currently encountered in clinical care are summarized in Table 1.

\section{Evolution of the Supraglottic Airway Device}

Dr Archie Brain is credited with the invention and development of the LMA in $1981 .^{2}$ The prototype device was crafted with a Goldman nasal mask fused with an obliquely cut endotracheal tube (ETT). The aim of this device was to obviate need for ETT placement and thereby

Table 1. Features of Current Supraglottic Airway Devices

\begin{tabular}{|c|c|c|c|c|c|}
\hline Device & Cuffed & Tube/Shaft & $\begin{array}{l}\text { Integrated } \\
\text { Bite Block }\end{array}$ & Reuse & Modifications \\
\hline \multicolumn{6}{|l|}{ First-generation devices } \\
\hline LMA Classic (LMA North America) & Yes & Diagonally cut & No & Yes & \\
\hline LMA Flexible (LMA North America) & Yes & Built-in coil for flexibility & No & Yes & \\
\hline $\begin{array}{l}\text { Intubating LMA (Fastrach; LMA } \\
\text { North America) }\end{array}$ & Yes & Short shaft to accommodate ETT & Yes & Yes & \\
\hline Ambu AuraOnce & Yes & Preformed curve & No & No & Softer, more flexible cuff than LMA \\
\hline Ambu Aura40 & Yes & Preformed curve & No & Yes & \\
\hline Ambu Aura-i & Yes & $\begin{array}{l}\text { Preformed curve, conduit for tracheal } \\
\text { tube }\end{array}$ & Yes & Yes & \\
\hline Ambu AuraFlex & Yes & Preformed curve, flexible tube & No & No & \\
\hline Ambu AuraStraight & Yes & More traditionally curved & No & No & \\
\hline Portex SSLM (Smiths Medical) & Yes & Disposable, PVC & No & No & \\
\hline ILA (LMA North America) & Yes & Conduit for tracheal tube & No & Both & Ridges to improve tube seal \\
\hline LT (VBM Medical) & Yes & Airway tube with 2 inflatable balloons & No & Both & Airway orifices, lateral hole in tube \\
\hline $\begin{array}{l}\text { CobraPLA (Engineered Medical } \\
\text { Systems) }\end{array}$ & Yes & Cobra head with ramp for ETT & No & Yes & \\
\hline \multicolumn{6}{|l|}{ Second-generation devices } \\
\hline LMA ProSeal (LMA North America) & Yes & Airway tube, gastric drain tube & Yes & Yes & Reliable seal, displacement diagnosis \\
\hline LMA Supreme (LMA North America) & Yes & Elliptical airway tube, gastric drain & Yes & No & $\begin{array}{l}\text { Flexibility, strong seal, placement } \\
\text { check }\end{array}$ \\
\hline LTS-II/G-LT (VBM Medical) & Yes & Airway tube with 2 inflatable balloons & Yes & Yes & Drain tube, pronounced in LTS-G \\
\hline i-gel (Intersurgical) & No & Rigid tube that acts as bite block & Yes & No & Creates anatomic seal \\
\hline air-Q (Mercury Medical) & Yes & $\begin{array}{l}\text { Short shaft allows standard ETT } \\
\text { insertion }\end{array}$ & Yes & No & Removable 15 -mm connector \\
\hline SLIPA (CurveAir Ltd) & No & $\begin{array}{l}\text { Lines pharynx to increase storage } \\
\text { capacity }\end{array}$ & No & No & Hollow, mimics pharynx \\
\hline Combitube (Nellcor Puritan Bennett) & Yes & Double cuff, double lumen & No & No & Oropharyngeal balloon \\
\hline $\begin{array}{l}\text { LMA }=\text { laryngeal mask airway } \\
\text { ETT = endotracheal tube } \\
\text { SSLM = soft seal laryngeal mask } \\
\text { PVC = polyvinyl chloride } \\
\text { ILA = intubating laryngeal airway } \\
\text { LT = laryngeal tube } \\
\text { PLA = perilaryngeal airway } \\
\text { LTS = laryngeal tube suction } \\
\text { G-LT = gastro-laryngeal tube } \\
\text { SLIPA = streamlined liner of the pharynx airway }\end{array}$ & & & & & \\
\hline
\end{tabular}




\section{Supraglottic Airway Devices}

reduce airway morbidity related to tracheal intubation. It is reported that Dr Brain tested LMA prototypes on $>7,000$ subjects before the initial commercial devices were launched in $1988 .{ }^{3} \mathrm{He}$ is also known to have publicly demonstrated the insertion of the LMA into his own pharynx using local anesthesia. ${ }^{1}$ Along with Dr Brain, Dr Chandy Verghese was instrumental in describing specific techniques and device modifications that have transformed the clinical value of the LMA. ${ }^{2-7}$

The LMA Classic received wide recognition in a short time and has had a major impact on anesthesia practice and airway management. ${ }^{8}$ After almost a decade of preliminary reports starting in 1983, the LMA was approved for sale in the United States. Over the first 3 y of its clinical availability, the LMA replaced the ETT as the airway management technique in $>40 \%$ of routine general anesthetics in one report. ${ }^{1}$ LMA use also increased independently of ETT declining rates, suggesting that ease of use allowed conversion of face-mask-only-based airway management to the LMA-based technique. There are several possible reasons for this observation. First, SADs, in general, and the LMA Classic, in particular, were extremely versatile and could be used in a variety of patient positions. ${ }^{9,10}$ Additionally, they offered a hands-free method of airway management associated with a low rate of failure and high patient satisfaction, likely related to reduced sore throat. ${ }^{11}$ Finally, first-generation SADs were developed during the era of propofol, a drug with extremely beneficial effects on the upper airway reflexes in comparison to alternatives such as barbiturates. ${ }^{12-14}$ With widespread use, it became clear that new designs were needed to deal with emerging problems and failures being reported. This quest for improved SADs first resulted in the invention of several devices with the ability to accommodate suction or nasogastric tubes. New features included more dependable PPV, disposability, integrated bite blocks, enhanced ability to function as conduits for ETT placement, and reduced risk of pulmonary aspiration of gastric contents. The last decade has seen a rapid rise in the number of clinical studies evaluating these second-generation SADs. A literature search of clinical trial publications on PubMed using the search terms "laryngeal mask," "supraglottic airway," and "supraglottic airway device" and the names of each of the first-generation and second-generation devices showed that the majority of studies were conducted on first-generation SADs (Fig. 1). The majority of clinical trials in the last few years have continued to use the LMA Classic, which has traditionally been considered the accepted standard (Table 2). Despite the fact that the LMA Classic is multiple-use with generic disadvantages related to infection risks and device performance decline over time, it still is in use in several countries. However, most developed countries use second-generation SADs, as

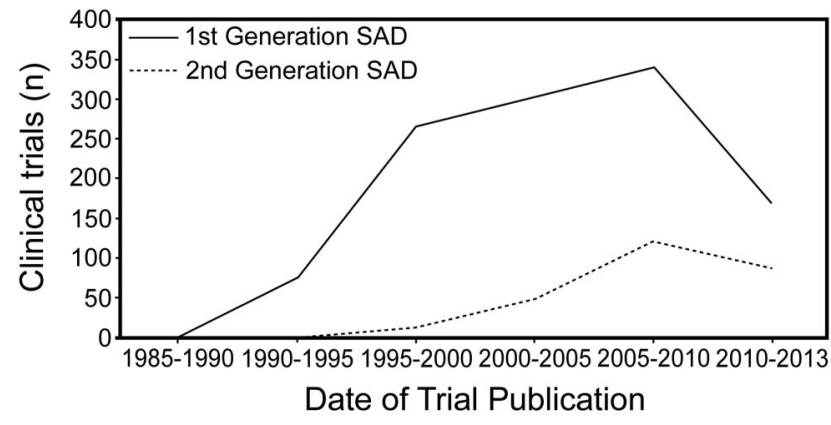

Fig. 1. Frequency distribution of clinical trials involving first-generation and second-generation supraglottic airway devices (SADs). A literature search of clinical trial publications on PubMed using the search terms "laryngeal mask," "supraglottic airway," and "supraglottic airway device," and the names of each of the first-generation and second-generation devices showed that the majority of studies were conducted on first-generation SADs. The majority of clinical trials continue to be based on the LMA Classic, which has traditionally been considered the accepted standard.

these provide exceptional advantages over the LMA Classic and similar devices.

\section{Clinical Use of Supraglottic Airway Devices}

SADs are now used in a wide variety of clinical indications. Their versatility and ease of use make them particularly valuable to caregivers practicing anesthesia, resuscitation, and intensive care. Unfortunately, several of these devices have not undergone rigorous real-time clinical evaluation, so efficiency and safety data are inadequate. The majority of literature on SADs has focused on the LMA family, particularly the first-generation devices. Over the last few years, current market shares of the second-generation SADs have grown substantially, making them more likely to be encountered in clinical use.

\section{Alternative to Tracheal Intubation for Routine Anesthesia}

The introduction of SADs resulted in a paradigm shift in airway management during anesthesia from a 2-choice (face mask vs ETT) to a 3-choice (face mask vs SAD vs ETT) model. Compared to tracheal intubation and extubation, the use of SADs is associated with more stability in hemodynamics, ${ }^{15}$ intracranial pressure, ${ }^{16}$ and intraocular pressure. ${ }^{17-19}$ There is a lower incidence of emergence cough and postoperative sore throat with SADs. A previous metaanalysis showed $17 \%$ incidence of sore throat with the LMA Classic compared with $39 \%$ incidence after tracheal intubation. ${ }^{11}$ Although initial clinical use was typically for anesthetized patients breathing spontaneously, SADs are now increasingly being used in patients who are paralyzed with muscle relaxants. This practice change has occurred because of significant device innovation and modification 
Table 2. Number of Randomized Trials Involving Supraglottic Airway Devices

\begin{tabular}{|c|c|c|c|c|c|c|c|}
\hline Device & 1985-1990 & 1990-1995 & 1995-2000 & 2000-2005 & 2005-2010 & 2010-2013 & Total \\
\hline LMA Classic & 5 & 73 & 235 & 253 & 279 & 142 & 987 \\
\hline LMA Flexible & 0 & 0 & 8 & 5 & 7 & 3 & 23 \\
\hline Intubating LMA & 0 & 1 & 23 & 39 & 26 & 15 & 104 \\
\hline LMA ProSeal & 0 & 0 & 3 & 37 & 61 & 27 & 128 \\
\hline LMA Supreme & 0 & 0 & 0 & 0 & 15 & 17 & 32 \\
\hline Ambu AuraOnce & 0 & 0 & 0 & 0 & 3 & 1 & 4 \\
\hline Ambu Aura-i & 0 & 0 & 0 & 0 & 0 & 1 & 1 \\
\hline SSLM & 0 & 0 & 0 & 5 & 13 & 3 & 21 \\
\hline ILA & 0 & 0 & 0 & 0 & 0 & 2 & 2 \\
\hline LT & 0 & 0 & 0 & 5 & 4 & 1 & 10 \\
\hline CobraPLA & 0 & 0 & 0 & 0 & 7 & 1 & 8 \\
\hline LTS-II/G-LT & 0 & 0 & 0 & 3 & 19 & 7 & 29 \\
\hline i-gel & 0 & 0 & 0 & 0 & 13 & 28 & 41 \\
\hline SLIPA & 0 & 0 & 0 & 1 & 5 & 5 & 11 \\
\hline Combitube & 0 & 1 & 10 & 8 & 7 & 3 & 29 \\
\hline $\begin{array}{l}\text { LMA = laryngeal mask } \\
\text { SSLM = soft seal laryn } \\
\text { ILA = intubating laryng } \\
\text { LT = laryngeal tube } \\
\text { PLA = perilaryngeal air } \\
\text { LTS = laryngeal tube st } \\
\text { G-LT = gastro-laryngea } \\
\text { SLIPA = streamlined lit }\end{array}$ & pharynx airway & & & & & & \\
\hline
\end{tabular}

Table 3. Effectiveness and Complications With Use of Supraglottic Airway Devices

\begin{tabular}{|c|c|c|c|c|c|c|}
\hline Device & $\begin{array}{c}\text { Insertion } \\
\text { Success }(\%)\end{array}$ & $\begin{array}{l}\text { First-Attempt } \\
\text { Success }(\%)\end{array}$ & $\begin{array}{l}\text { Airway Leak Pressure } \\
\qquad\left(\mathrm{cm} \mathrm{H}_{2} \mathrm{O}\right)\end{array}$ & $\begin{array}{c}\text { Failed } \\
\text { Placement }(\%)\end{array}$ & $\begin{array}{c}\text { Airway } \\
\text { Injury (\%) }\end{array}$ & References \\
\hline LMA Classic & $88.6-100$ & $77.1-100$ & $16-26.1$ & $0.40-0.52$ & $1.0-40.0$ & $11,20-27$ \\
\hline LMA ProSeal & $98.4-100$ & $82.8-94.3$ & $19.27-34$ & & $0.5-17.7$ & $20,21,23,26,28-33$ \\
\hline LMA Supreme & $97.0-100$ & $88.0-98.0$ & $22.8-34.6$ & & $0-14.0$ & $1,27,31-36$ \\
\hline Ambu AuraOnce & $92-100$ & $92-92.4$ & $18-20$ & & Little data & 1 \\
\hline LT & $90-94$ & $86-90$ & $22-40$ & $10-41.2$ & $0-6$ & $1,9,21,24$ \\
\hline CobraPLA & $100 \%$ & $82-100$ & 22.5 & $0-6.9$ & $4-22$ & 1 \\
\hline LTS-II/G-LT & $68.8-100$ & $68.8-93.3$ & $24-31$ & $10-41.2$ & $0-6$ & $1,20,28,30$ \\
\hline i-gel & $95.9-100$ & $85-96$ & $20-30$ & $0-3.86$ & $1.22-20.1$ & $20,29,34,35,37$ \\
\hline Combitube & $90.0-93.8$ & $37.5-86.7$ & $34-40$ & $3-10$ & $4.0-70.0$ & $23,28,38,39$ \\
\hline \multicolumn{7}{|c|}{$\begin{array}{l}\text { LMA = laryngeal mask airway } \\
\text { LT = laryngeal tube } \\
\text { PLA = perilaryngeal airway } \\
\text { LTS = laryngeal tube suction } \\
\text { G-LT = gastro-laryngeal tube }\end{array}$} \\
\hline
\end{tabular}

allowing higher seal pressures. Most first-generation SADs develop an air leak during PPV of $16-20 \mathrm{~cm} \mathrm{H}_{2} \mathrm{O}$. A few studies show higher seal pressures in selected populations. Second-generation devices maintain pharyngeal seals with pressures of $25-28 \mathrm{~cm} \mathrm{H}_{2} \mathrm{O}$. This has permitted clinically satisfactory conditions during the use of SADs in a variety of complex surgical procedures, including laparoscopic surgery, in which abdominal pressures are necessarily high and cause encroachment on diaphragm excursion. The detailed description of individual SADs is beyond the scope of this article, as there are $>30$ such devices in the market. A summary of the devices and their effectiveness data are presented in Tables 1 and 3.

\section{Tracheal Intubation Aide}

Several techniques have been described to facilitate tracheal intubation using SADs. The typical scenario in which this technique is useful is when the LMA has been placed for rescue of failed direct laryngoscopy or failed intuba- 


\section{Supraglottic Airway Devices}

tion. The SAD may be used for blind or fiberoptic bronchoscope-guided methods to aid intubation. A specific advantage of using SADs is the ability to continue ventilating and anesthetizing the patient through the SAD until formal tracheal intubation is achieved. Additional advantages of specific devices include better visualization of glottic structures using a flexible fiberoptic bronchoscope and ability to insert the ETT through the SAD. This specific functionality is perhaps one of the more important considerations when deciding to purchase SADs for hospital use. SADs that are associated with high success rates as a conduit for tracheal intubation, without need for significant device modification or maneuvers, are likely to be best for management of unanticipated difficult airway scenarios. Several design characteristics limit the ability of individual SADs to function as effective conduits for ETT placement. Some SADs have bars on the pharyngeal bowl to prevent the epiglottis from falling back into the shaft. This imposes a mechanical impediment to easy passage of both the fiberoptic bronchoscope and ETT. These bars may be cut or removed to permit easier passage of the ETT but are likely to still impede visualization, intubation, or both. The length of the ETT may be inadequate to achieve satisfactory depth of insertion of the ETT into the trachea. This deficiency may result in dislodgement of the ETT during removal of the LMA. Some SADs have short stems (air-Q [Mercury Medical, Clearwater, Florida], Aura-i [Ambu, Glen Burnie, Maryland], and LMA Fastrach [LMA North America]) to permit easy ETT insertion without risk of accidental extubation as detailed above. Another way to achieve adequate insertion depth of the ETT is to use longer ETTs such as the Ring-Adair-Elwyn ETT. The LMA Fastrach is packaged with a long ETT in addition to having a short stem. The internal diameter of the SAD may prevent use of ETTs of the appropriate size. The LMA family typically accepts ETTs of smaller sizes (6.0-6.5-mm inner diameter tubes). Some devices (air-Q and LMA Classic) permit removal of the $\mathrm{SAD} 15-\mathrm{mm}$ connector, thereby accommodating larger ETTs. Some newer devices (air-Q and Aura-i) allow use of larger ETTs of up to 8.0-mm inner diameter. Other techniques have been described to aide tracheal intubation through the SADs. The Aintree catheter may be used over a fiberoptic bronchoscope to access the trachea through the SAD. ${ }^{40,41}$ The SAD can then be removed while keeping the Aintree catheter in place, and the ETT can be advanced over the Aintree catheter into the trachea. Other 2-step techniques involve use of a gum elastic bougie insertion through the SAD as first step, followed by advancing the ETT over the bougie. Three-step techniques involve insertion of a guidewire through a fiberoptic bronchoscope into the trachea, followed by removal of SAD, railroading an Aintree intubating catheter over the guidewire, and railroading the ETT over the Aintree catheter.

\section{Blind Tracheal Intubation Through Supraglottic Airway Devices}

In general, it is advisable to use fiberoptic bronchoscope-guided techniques to ensure greater success of tracheal intubation through the SAD. However, blind insertion of the ETT through an SAD may be indicated in certain clinical scenarios and is reported to have success rates of $50-97 \%$ with several SADs. ${ }^{22}$ Conversely, this statistic also reflects a 1 -in-2 to 1 -in-33 chance of failing to intubate the trachea blindly through the SAD, making fiberoptic bronchoscope-guided techniques safer. Another caution is to avoid extrapolation of data from controlled study environments to real-world clinical scenarios where SADs are used to rescue anatomically challenging airways. There are inadequate data to support generalization of individual SAD success rates with intubation to emergent scenarios. The LMA Fastrach was used in a multicenter study of 254 subjects with known difficult airways. The overall success rate for blind intubations through the LMA Fastrach was $96.5 \% .42$ There are inadequate data on individual devices to support one device over another. The pharyngeal anatomical dimensions tend to favor passage of the ETT into the esophagus more readily than into the trachea when inserted through most first-generation devices. The air-Q and intubating LMA Fastrach ${ }^{43}$ have design advantages that may increase success rates of blind tracheal intubation.

\section{Fiberoptic-Guided Tracheal Intubation Through Supraglottic Airway Devices}

As the recommended technique, fiberoptic bronchoscope-guided ETT placement through the SAD has significant benefits as listed above. A complete view of the glottis is possible in the majority of patients when the fiberoptic bronchoscope is inserted into the SAD. ${ }^{42}$ It is important to note that a clear view of any glottic structure may be lacking in up to $18 \%$ of cases, even though there is no evidence of airway obstruction. ${ }^{44-47}$ This finding highlights the value of the SAD in maintaining upper airway patency but also reflects inherent limits to success of this tracheal intubation technique. Figures 2 and 3 depict blind and fiberoptic-guided intubations through an SAD.

\section{Rescue Airway: Difficult Intubation, Failed Intubation, Cannot Intubate, and Cannot Ventilate}

The early recognition of the value of the LMA in management of difficult airway situations has influenced the widespread acceptance of SAD technology in clinical practice. SADs are capable of rescuing emergent situations when traditional attempts to ventilate or oxygenate the patient fail. The American Society of Anesthesiologists' 

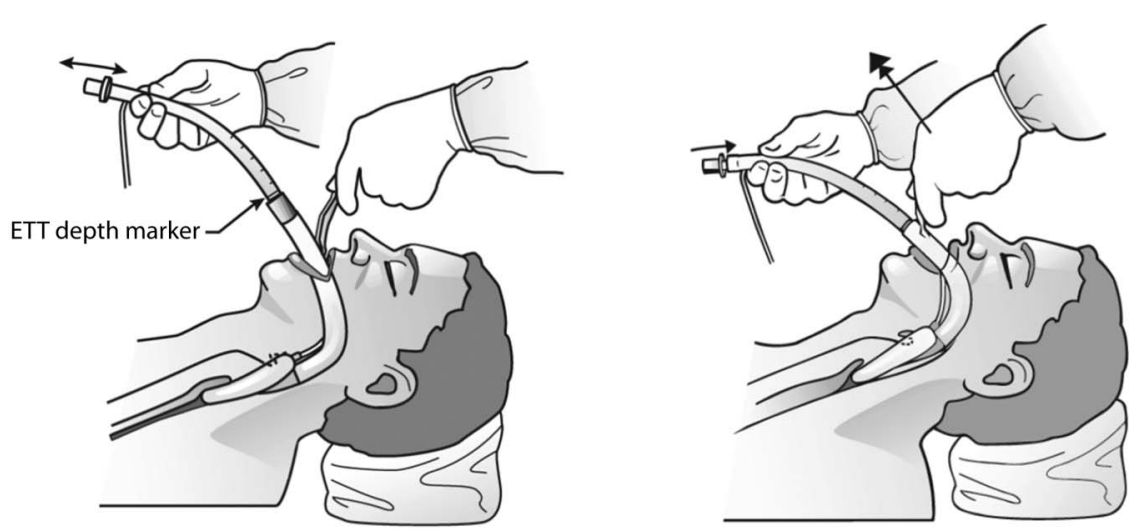

Fig. 2. Blind intubation through a supraglottic airway device (SAD), in this case, the laryngeal mask airway (LMA) Fastrach. During blind intubation, it is important to align the tracheal tube with the glottic opening, as the figure demonstrates. ETT = endotracheal tube. Courtesy Teleflex Medical.

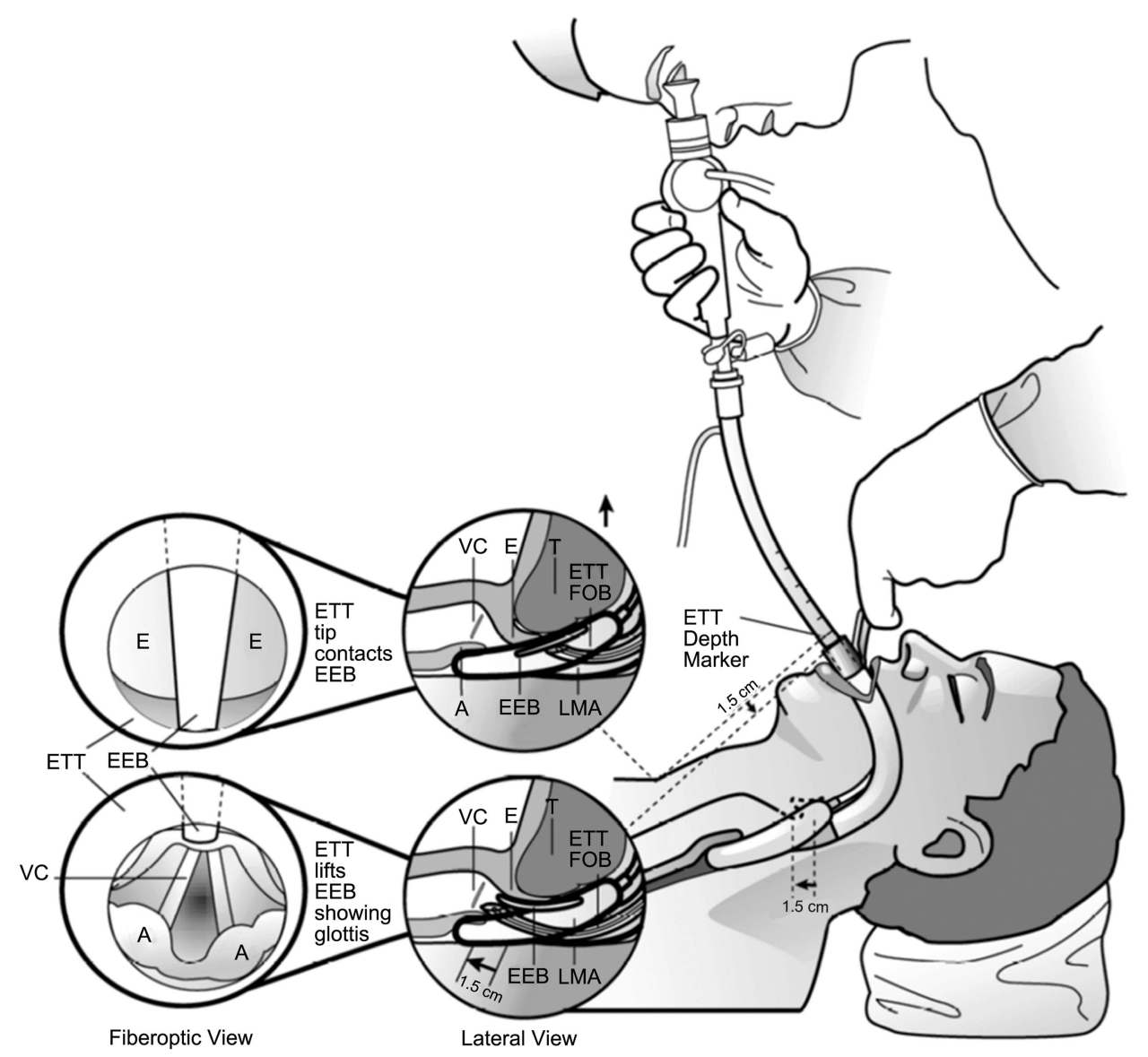

Fig. 3. Representative example of the use of a fiberoptic bronchoscope (FOB) to guide intubation through a supraglottic airway device. The glottic opening should be visible on advancement of the fiberoptic bronchoscope positioned just beyond the bowl of the airway device. It should then be possible to advance the tracheal tube into the trachea under direct vision. The full view of the glottic opening may not be achieved in all situations. $\mathrm{E}=$ epiglottis; $\mathrm{VC}=$ vocal cords; $\mathrm{ETT}$ = endotracheal tube; $\mathrm{EEB}$ = epiglottic elevating bar; $\mathrm{LMA}=$ laryngeal mask airway; $\mathrm{T}=$ tongue; $\mathrm{A}=$ arytenoids. Courtesy Teleflex Medical.

difficult airway algorithm has a prominent place for the use of SADs in rescue capacity during such scenarios. Rigorous evidence of efficacy of the LMA versus face mask ventilation exists only for patients without difficult airways. There are several case reports that describe the value of the LMA in maintaining or restoring ventilation 


\section{Supraglottic Airway Devices}

in adult subjects with difficult airways. ${ }^{48-51}$ An observational study of LMA in subjects in whom mask ventilation or tracheal intubation was impossible showed $94.1 \%$ success rates for rescue ventilation. ${ }^{51}$ The LMA has been shown to be efficient in preventing significant desaturation in pediatric patients with difficult airways. ${ }^{52,53}$ Similar success rates for ventilation and oxygenation were seen with the laryngeal tube in $95 \%$ of patients with pharyngeal and laryngeal tumors. ${ }^{54}$ Various SADs aid successful tracheal intubation in situations in which traditional methods have failed. Use of fiberoptic techniques through the intubating LMA is associated with significantly higher frequency of first-attempt successful intubation for patients with predicted or simulated difficult airways compared to standard fiberoptic intubation. ${ }^{9,55}$ The intubating LMA was shown to have extremely high success rates for blind and fiberoptic bronchoscope-guided intubations (97 and 100\%, respectively) in patients with Cormack-Lehane grade 4 views; immobilized cervical spines; airways distorted by tumors, surgery, or radiation therapy; and stereotactic frames. ${ }^{42}$ Other observational studies cite $71.4-100 \%$ intubation success rates in patients with difficult airways with the intubating LMA. ${ }^{56-61}$

\section{Resuscitation and Prehospital Airway Management}

Airway management during cardiopulmonary resuscitation may have significant impact on survival. ${ }^{62,63}$ Invasive ventilation itself may have deleterious effects on physiology and likelihood of survival. ${ }^{64,65}$ Tracheal intubation is more likely to be difficult in the emergent situations ${ }^{66}$ and often requires cessation of chest compressions for significant durations. Interruption of chest compressions is associated with immediate cessation of cardiac output. Theoretically, SADs with significant ease of use may have advantages to tracheal intubation during cardiopulmonary resuscitation. However, clinical evidence is contradictory, pointing to worse outcomes from prehospital cardiac arrests with invasive airway placement. In a large propensity score-matched cohort (357,228 subjects), need for tracheal intubation (adjusted odds ratio $0.45,95 \%$ CI $0.37-0.55$ ) or SAD placement (adjusted odds ratio $0.36,95 \%$ CI $0.33-$ 0.39 ) was associated with significantly lower adjusted odds of neurologically favorable survival compared with bagvalve-mask ventilation. It is unknown whether this finding reflects greater arrest severity in patients needing advanced airway management or increased morbidity directly related to placement of the SAD. A future study (REVIVEAirways) proposes to compare the ventilation success of 2 newer SADs, the i-gel (Intersurgical, Wokingham, Berkshire, United Kingdom) and the LMA Supreme (LMA North America), to usual practice during the initial airway management of out-of-hospital cardiac arrests. ${ }^{67}$ This study may help cast further light on the value of SADs in car- diopulmonary resuscitation. The laryngeal tube is widely appreciated as an acceptable method of airway management during cardiopulmonary resuscitation and is included in the 2010 International Consensus on Cardiopulmonary Resuscitation and Emergency Cardiovascular Care guidelines. ${ }^{68}$ Its ease of insertion may be one of the reasons for its wider acceptance into resuscitation guidelines. ${ }^{69-73} \mathrm{An}$ other major consideration during prehospital airway management is cervical spine movement during placement of the SAD or ETT. The LMA (median $2.5^{\circ}$ ) and the combitube (median $1.5^{\circ}$; Nellcor Puritan Bennett, Pleasanton, California) caused less extension of the upper cervical vertebrae ( $\mathrm{C} 0-\mathrm{C} 1)$ compared with the McCoy laryngoscope $\left(\right.$ median $\left.7^{\circ}\right)$. A similar reduction in extension was noted at the $\mathrm{C} 2-\mathrm{C} 3$ area of the cervical spine. ${ }^{74}$

\section{Tracheal Extubation Aide}

Because SADs are associated with significantly less cough and increases in intracranial or intraocular pressures compared to the ETT, they may have a role to play in smooth emergence from anesthesia. The SAD may be placed after removal of the ETT or placed alongside the ETT before its removal. This approach may be particularly helpful in situations in which airway and hemodynamic reflexes are not desired or when surgical incisions prevent the application of the face mask. ${ }^{75-78}$

\section{Complications of Supraglottic Airway Devices}

Complications related to SAD are rare and therefore likely to become apparent years after introduction into clinical use. The bevy of SADs on the market is understudied using large observational data sets reflecting realworld clinical use. The LMA family remains one of the best studied, and estimates of effectiveness and safety are likely to be generalizable. Table 3 summarizes the key reported complications with each type of SAD. The estimates are provided as a range of data to reflect the variability in both success and complications in different study environments.

\section{Ventilatory Failure}

Despite significant advances in safety with the development of second-generation devices, there is a significant failure rate with SADs, which may translate to inadequate performance especially in emergent scenarios. The failure rates range from 0 to $41 \%$, with the majority of devices having failure rates of $0-5 \%$ (Table 3 ). It is important to recognize that specific design characteristics may contribute to this failure rate. For instance, although the laryngeal tube is arguably the easiest to insert, it tends to rotate along its long axis, causing misalignment of the laryngeal open- 


\section{Supraglottic Airway Devices}
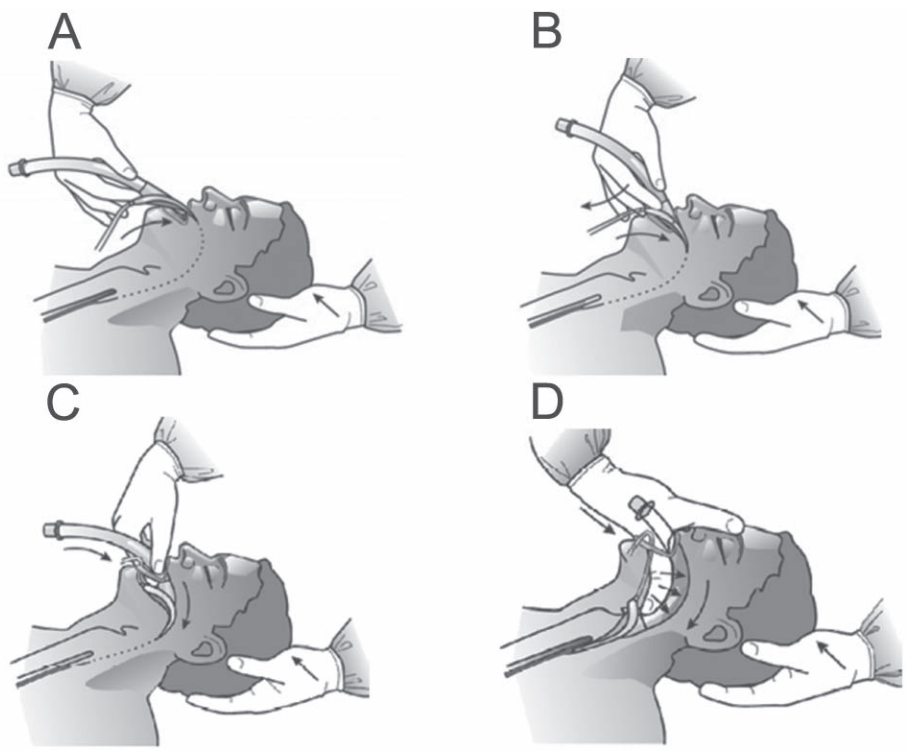

Fig. 4. Classic technique for insertion of a laryngeal mask airway (LMA) device. With the neck flexed and the head extended by pushing the head from behind with one hand, the LMA is inserted into the mouth with the other hand (A). The inserting hand is positioned like a pen, with the index finger placed at the junction of the cuff and tube. The LMA tip is pushed up against the hard palate after verifying that it is lying flat against the palate and that the tip is not folded over. Using the index finger, the mask is pushed into the patient's mouth, still maintaining pressure against the palate $(B)$. As the mask moves in, the index finger maintains pressure against the posterior pharyngeal wall to avoid the epiglottis (C). The index finger is fully inside the mouth at the end of insertion (D). The other hand holds the LMA while the inserting finger is removed from the mouth. The cuff is inflated without holding the tube, permitting the device to position itself correctly. Courtesy Teleflex Medical.

ing with the glottis and subsequent loss of ventilation. Similarly, preformed SADs such as the Ambu Aura-i may fail because the rigid dimensions of the shaft and curve may not adequately compensate for anatomic variability of the upper airway seen in general populations. The risk of ventilatory failure after insertion of the SAD can be reduced by sticking to simple rules described in the section below on tips and tricks for successful insertion of SADs.

\section{Airway Injury}

Postoperative sore throat occurs in $0-70 \%$ of patients managed with SADs. ${ }^{79,80}$ Contributing factors include device type and size, insertion technique, and cuff pressure. ${ }^{81-85}$ Proactive measurement and reduction of cuff pressures to $<60 \mathrm{~cm} \mathrm{H}_{2} \mathrm{O}$ have been shown to reduce the incidence of sore throat. ${ }^{82}$ Tongue congestion and edema may occur if the SAD is not inserted deeply enough or the cuff is overinflated. This malposition is more likely to occur if the cuff is partially or fully inflated prior to insertion. Compression injuries to pharyngeal nerves, including the lingual, hypoglossal, and recurrent laryngeal nerves, have been described. ${ }^{86-88}$ These are typically neuropraxic in nature, with spontaneous recovery expected. The frenulum of the tongue may be avulsed if the tongue gets lodged in the bowl of the SAD. ${ }^{89}$ Device materials with extremely low coefficients of friction such as the
LMA Classic and i-gel may be associated with fewer injuries as a result.

\section{Pulmonary Aspiration of Gastric Contents}

SADs are associated with an extremely low incidence of pulmonary aspiration of gastric contents during elective surgery in fasted patients, but several case reports exist for this complication..$^{90,91}$ SADs may be associated with reduced lower esophageal sphincter tone in comparison with face mask ventilation. ${ }^{92}$ Previous estimates of pulmonary aspiration range from $\sim 0.84$ to 2 per 10,000 patients with the LMA. ${ }^{93-95}$ Studies of pulmonary aspiration rates during PPV showed no increase in risk of aspiration with LMA use ( 3 per 35,630 procedures) compared to ETT (7 per 30,082 procedures). ${ }^{96}$ Specific design characteristics of SADs contribute to the extremely low incidence of regurgitation and pulmonary aspiration of gastric contents. Most first-generation and second-generation SADs have extremely high esophageal seal pressures $(>50-60 \mathrm{~cm}$ $\mathrm{H}_{2} \mathrm{O}$ ). This esophageal seal pressure refers to the opening pressure of the esophagus and is different from the pharyngeal leak pressure, which is an indication of the airway pressure at which there is leak of tidal volume into the atmosphere. Second-generation devices have also been shown to effectively vent gastric regurgitant fluid, thereby reducing the risk of aspiration. ${ }^{97,98}$ The $\mathrm{i}$-gel has a specific 


\section{Supraglottic Airway Devices}

design at the tip that results in lower esophageal seal pressures, but this has not been seen to increase risk of aspiration, likely related to the presence of the esophageal drain tube. Despite these safety features, peak airway pressures may have an extremely important part in preventing esophageal insufflation of air and potential increases in pulmonary aspiration risk. Cadaver studies indicate that airway pressures $>20 \mathrm{~cm} \mathrm{H}_{2} \mathrm{O}$ are associated with varying degrees of esophageal insufflation even with secondgeneration SADs, including the LMA Supreme and LMA ProSeal (LMA North America), LTS-D and LTS-II laryngeal tubes (VBM Medical, Noblesville, Indiana), combitube, and i-gel..$^{99}$

\section{Contraindications for Use of Supraglottic Airway Devices}

Given that the most impactful complications with SADs relate to ventilatory failure and aspiration, classic contraindications include patient factors that increase such risks. Device failure related to inadequate ventilation is more likely to occur with obesity and obstructive airways disease, whereas aspiration risks are increased with active gastroesophageal reflux, intestinal obstruction, hiatal hernia, trauma, and intoxication. Patients with traumatic airway injuries are more likely to develop complications related to SAD placement.

\section{Tips and Tricks for Successful Use of Supraglottic Airway Devices}

The following generic precautions will help improve success with use of SADs.

- Patient Selection: In elective situations, most patients with normal lung compliance who have fasted can be mechanically ventilated effectively with the SAD. In emergent situations, the SAD is often used as a rescue device.

- Size Selection: If unsure, check the package cover for size information. In general, larger cuffed SADs tend to function better with PPV.

- Patient Position: Leaving the patient in sniffing position helps the correct placement of most SADs except the combitube, which specifies neutral head position.

- Insertion Technique: Carefully follow the correct insertion technique to ensure optimal positioning of the SAD in the airway. Figure 4 shows a common method of insertion of the LMA using the forefinger technique (or pencil grip). The i-gel can be inserted by holding the device like a soup spoon. In general, semi-inflated cuffs tend to result in inadequate depth placement of the LMA. The LMA ProSeal can be inserted using the classic LMA technique, using the metal introducer, or inserting a gum elastic bougie upside down into the esophagus and then advancing the LMA ProSeal over it by inserting the bougie through the drain tube of the device.

- Fixation Technique: Fixing the LMA to the maxilla helps secure the depth position. This ensures proper contact between the LMA tip and the esophagus and prevents gastric insufflation.

- Auscultation: Always auscultate over the stomach to ensure that gastric insufflation does not take place.

- Ventilatory Parameters: Limit tidal volumes to $8 \mathrm{~mL} / \mathrm{kg}$, and control the end-tidal carbon dioxide by adjusting the breathing frequency.

- Second Generation Devices: Do not use the gastric channel if there is an excessive air leak through the gastric channel, esophageal varices, esophageal trauma, upper gastrointestinal bleed, history of upper gastrointestinal surgery, or coagulopathy.

- Removal Technique: Wait for full recovery from anesthesia. Do not pull on the SAD if the patient is biting down on the shaft. Usually, patients emerge smoothly with SADs.

\section{Summary}

Recent advances in SAD design have significantly enhancement function and clinical utility. SADs continue to be an important mode of rescue ventilation in patients in whom mask ventilation or tracheal intubation is impossible. Despite these advances, specific concerns such as ventilatory failure, airway injury, and pulmonary aspiration of gastric contents remain, necessitating careful patient selection and appropriate techniques for the successful use of these devices.

\section{REFERENCES}

1. Hagberg C. Benumof and Hagberg's airway management, 3rd edition. Philadelphia: Elsevier; 2012.

2. Brain AI. The laryngeal mask-a new concept in airway management. Br J Anaesth 1983;55(8):801-805.

3. Brain AI. The development of the Laryngeal Mask-a brief history of the invention, early clinical studies and experimental work from which the Laryngeal Mask evolved. Eur J Anaesthesiol Suppl 1991; 4:5-17.

4. Gerstein NS, Braude DA, Hung O, Sanders JC, Murphy MF. The Fastrach Intubating Laryngeal Mask Airway: an overview and update. Can J Anaesth 2010;57(6):588-601.

5. Brain AI. The laryngeal mask airway-a possible new solution to airway problems in the emergency situation. Arch Emerg Med 1984; 1(4):229-232

6. Brain AI, McGhee TD, McAteer EJ, Thomas A, Abu-Saad MA, Bushman JA. The laryngeal mask airway. Development and preliminary trials of a new type of airway. Anaesthesia 1985;40(4):356361. 


\section{Supraglottic Airway Devices}

7. Brain AI, Verghese C, Strube PJ. The LMA 'ProSeal'-a laryngeal mask with an oesophageal vent. Br J Anaesth 2000;84(5):650-654.

8. Brodrick PM, Webster NR, Nunn JF. The laryngeal mask airway. A study of 100 patients during spontaneous breathing. Anaesthesia 1989;44(3):238-241.

9. Asai T, Eguchi Y, Murao K, Niitsu T, Shingu K. Intubating laryngeal mask for fibreoptic intubation-particularly useful during neck stabilization. Can J Anaesth 2000;47(9):843-848.

10. McCaughey W, Bhanumurthy S. Laryngeal mask placement in the prone position. Anaesthesia 1993;48(12):1104-1105.

11. Brimacombe J. The advantages of the LMA over the tracheal tube or facemask: a meta-analysis. Can J Anaesth 1995;42(11):1017-1023.

12. Scanlon P, Carey M, Power M, Kirby F. Patient response to laryngeal mask insertion after induction of anaesthesia with propofol or thiopentone. Can J Anaesth 1993;40(9):816-818.

13. Chen CH, Yang YL, Chen WM, Shyr MH. Comparison of the anesthesia profiles between sevoflurane-nitrous oxide and propofolnitrous oxide conveyed by laryngeal mask airway in patients undergoing ambulatory gynecological surgery. Acta Anaesthesiol Taiwan 2006;44(2):101-107.

14. Erhan E, Ugur G, Gunusen I, Alper I, Ozyar B. Propofol-not thiopental or etomidate-with remifentanil provides adequate intubating conditions in the absence of neuromuscular blockade. Can J Anaesth 2003;50(2):108-115.

15. Wilson IG, Fell D, Robinson SL, Smith G. Cardiovascular responses to insertion of the laryngeal mask. Anaesthesia 1992;47(4):300-302.

16. Braude N, Clements EA, Hodges UM, Andrews BP. The pressor response and laryngeal mask insertion. A comparison with tracheal intubation. Anaesthesia 1989;44(7):551-554.

17. Agrawal G, Agarwal M, Taneja S. A randomized comparative study of intraocular pressure and hemodynamic changes on insertion of proseal laryngeal mask airway and conventional tracheal intubation in pediatric patients. J Anaesthesiol Clin Pharmacol 2012;28(3):326-329.

18. Ismail SA, Bisher NA, Kandil HW, Mowafi HA, Atawia HA. Intraocular pressure and haemodynamic responses to insertion of the i-gel, laryngeal mask airway or endotracheal tube. Eur J Anaesthesiol 2011;28(6):443-448.

19. Igboko JO, Desalu I, Akinsola FB, Kushimo OT. Intraocular pressure changes in a Nigerian population-effects of tracheal tube and laryngeal mask airway insertion and removal. Niger Postgrad Med J 2009;16(2):99-104.

20. Cook T, Howes B. Supraglottic airway devices: recent advances. Contin Educ Anaesth Crit Care Pain 2010;11(2):56-61.

21. Bein B, Scholz J. Supraglottic airway devices. Best Pract Res Clin Anaesthesiol 2005;19(4):581-593.

22. Brimacombe JR. Laryngeal mask anaesthesia: principles and practice, 2nd edition. Philadelphia: Saunders; 2005.

23. Oczenski W, Krenn H, Dahaba AA, Binder M, El-Schahawi-Kienzl I, Kohout S, et al. Complications following the use of the Combitube, tracheal tube and laryngeal mask airway. Anaesthesia 1999; 54(12):1161-1165.

24. Ratajczyk P, Małachowska B, Gaszyńska E, Gaszyński T. A randomised comparison between Cobra PLA and classic laryngeal mask airway and laryngeal tube during mechanical ventilation for general anaesthesia. Anaesthesiol Intensive Ther 2013;45(1):20-24.

25. Galgon RE, Schroeder K, Joffe AM. The self-pressurising air-Q Intubating Laryngeal Airway for airway maintenance during anaesthesia in adults: a report of the first 100 uses. Anaesth Intensive Care 2012;40(6):1023-1027.

26. Das B, Jamil SN, Mitra S, Varshney RK. A prospective, randomized, single-blinded, comparative study of Classic Laryngeal Mask Airway and ProSeal Laryngeal Mask Airway in pediatric patients. J Anaesthesiol Clin Pharmacol 2012;28(3):318-321.
27. Ali A, Canturk S, Turkmen A, Turgut N, Altan A. Comparison of the laryngeal mask airway Supreme and laryngeal mask airway Classic in adults. Eur J Anaesthesiol 2009;26(12):1010-1014.

28. Bein B, Carstensen S, Gleim M, Claus L, Tonner PH, Steinfath M, et al. A comparison of the Proseal laryngeal mask airway, the laryngeal tube $\mathrm{S}$ and the oesophageal-tracheal combitube during routine surgical procedures. Eur J Anaesthesiol 2005;22(5):341-346.

29. Carron M, Veronese S, Gomiero W, Foletto M, Nitti D, Ori C, Freo U. Hemodynamic and hormonal stress responses to endotracheal tube and ProSeal Laryngeal Mask Airway for laparoscopic gastric banding. Anesthesiology 2012;117(2):309-320.

30. Cook TM, Cranshaw J. Randomized crossover comparison of ProSeal Laryngeal Mask Airway with Laryngeal Tube Sonda during anaesthesia with controlled ventilation. Br J Anaesth 2005;95(2):261-266.

31. Hosten T, Gurkan Y, Ozdamar D, Tekin M, Toker K, Solak M. A new supraglottic airway device: LMA-Supreme, comparison with LMA-Proseal. Acta Anaesthesiol Scand 2009;53(7):852-857.

32. Lee AK, Tey JB, Lim Y, Sia AT. Comparison of the single-use LMA Supreme with the reusable ProSeal LMA for anaesthesia in gynaecological laparoscopic surgery. Anaesth Intensive Care 2009;37(5): 815-819.

33. Eschertzhuber S, Brimacombe J, Hohlrieder M, Keller C. The laryngeal mask airway Supreme-a single use laryngeal mask airway with an oesophageal vent. A randomised, cross-over study with the laryngeal mask airway ProSeal in paralysed, anaesthetised patients. Anaesthesia 2009;64(1):79-83.

34. Chew EE, Hashim NH, Wang CY. Randomised comparison of the LMA Supreme with the I-Gel in spontaneously breathing anaesthetised adult patients. Anaesth Intensive Care 2010;38(6):1018-1022.

35. Teoh WH, Lee KM, Suhitharan T, Yahaya Z, Teo MM, Sia AT. Comparison of the LMA Supreme vs the i-gel in paralysed patients undergoing gynaecological laparoscopic surgery with controlled ventilation. Anaesthesia 2010;65(12):1173-1179.

36. Timmermann A, Cremer S, Eich C, Kazmaier S, Bräuer A, Graf BM, Russo SG. Prospective clinical and fiberoptic evaluation of the Supreme laryngeal mask airway. Anesthesiology 2009;110(2):262-265.

37. Hughes C, Place K, Berg S, Mason D. A clinical evaluation of the $\mathrm{I}_{\text {-gel }}{ }^{\mathrm{TM}}$ supraglottic airway device in children. Paediatr Anaesth 2012; 22(8):765-771.

38. Gaitini LA, Vaida SJ, Mostafa S, Yanovski B, Croitoru M, Capdevila MD, et al. The Combitube in elective surgery: a report of 200 cases. Anesthesiology 2001;94(1):79-82.

39. Bishop MJ, Kharasch ED. Is the Combitube a useful emergency airway device for anesthesiologists? Anesth Analg 1998;86(5):11411142 .

40. Atherton DP, O'Sullivan E, Lowe D, Charters P. A ventilationexchange bougie for fibreoptic intubations with the laryngeal mask airway. Anaesthesia 1996;51(12):1123-1126.

41. Higgs A, Clark E, Premraj K. Low-skill fibreoptic intubation: use of the Aintree Catheter with the classic LMA. Anaesthesia 2005;60(9): 915-920.

42. Ferson DZ, Rosenblatt WH, Johansen MJ, Osborn I, Ovassapian A. Use of the intubating LMA-Fastrach in 254 patients with difficultto-manage airways. Anesthesiology 2001;95(5):1175-1181.

43. Halwagi AE, Massicotte N, Lallo A, Gauthier A, Boudreault D, Ruel M, Girard F. Tracheal intubation through the i-gel supraglottic airway versus the LMA Fastrach: a randomized controlled trial. Anesth Analg 2012;114(1):152-156.

44. Jagannathan N, Sommers K, Sohn LE, Sawardekar A, Shah RD, Mukherji II, et al. A randomized equivalence trial comparing the i-gel and laryngeal mask airway Supreme in children. Paediatr Anaesth 2013;23(2):127-133.

45. Jagannathan N, Sohn LE, Sawardekar A, Gordon J, Shah RD, Mukherji II, et al. A randomized trial comparing the Ambu Aura-i 


\section{Supraglottic Airway Devices}

with the air-Q intubating laryngeal airway as conduits for tracheal intubation in children. Paediatr Anaesth 2012;22(12):1197-1204.

46. Jagannathan N, Sohn LE, Mankoo R, Langen KE, Mandler T. A randomized crossover comparison between the Laryngeal Mask Airway-Unique and the air-Q intubating laryngeal airway in children. Paediatr Anaesth 2012;22(2):161-167.

47. Theiler LG, Kleine-Brueggeney M, Kaiser D, Urwyler N, Luyet C, Vogt A, et al. Crossover comparison of the laryngeal mask Supreme and the i-gel in simulated difficult airway scenario in anesthetized patients. Anesthesiology 2009;111(1):55-62.

48. Augoustides JG, Groff BE, Mann DG, Johansson JS. Difficult airway management after carotid endarterectomy: utility and limitations of the Laryngeal Mask Airway. J Clin Anesth 2007;19(3):218221.

49. Fundingsland BW, Benumof JL. Difficulty using a laryngeal mask airway in a patient with lingual tonsil hyperplasia. Anesthesiology 1996;84(5):1265-1266.

50. Kidani DC, Shah NK. The use of a laryngeal mask airway after a prolonged suspension laryngoscopy to preserve a vocal cord fat graft. Anesth Analg 2007;105(6):1753-1754

51. Parmet JL, Colonna-Romano P, Horrow JC, Miller F, Gonzales J, Rosenberg $\mathrm{H}$. The laryngeal mask airway reliably provides rescue ventilation in cases of unanticipated difficult tracheal intubation along with difficult mask ventilation. Anesth Analg 1998;87(3):661-665.

52. Mizushima A, Wardall GJ, Simpson DL. The laryngeal mask airway in infants. Anaesthesia 1992;47(10):849-851.

53. Rowbottom SJ, Simpson DL, Grubb D. The laryngeal mask airway in children. A fibreoptic assessment of positioning. Anaesthesia 1991; 46(6):489-491.

54. Winterhalter M, Kirchhoff K, Gröschel W, Lüllwitz E, Heermann R, Hoy L, et al. The laryngeal tube for difficult airway management: a prospective investigation in patients with pharyngeal and laryngeal tumours. Eur J Anaesthesiol 2005;22(9):678-682.

55. Bhatnagar S, Mishra S, Jha RR, Singhal AK, Bhatnagar N. The LMA Fastrach facilitates fibreoptic intubation in oral cancer patients. Can J Anaesth 2005;52(6):641-645.

56. Frappier J, Guenoun T, Journois D, Philippe H, Aka E, Cadi P, et al. Airway management using the intubating laryngeal mask airway for the morbidly obese patient. Anesth Analg 2003;96(5):1510-1515.

57. Fukutome T, Amaha K, Nakazawa K, Kawamura T, Noguchi H. Tracheal intubation through the intubating laryngeal mask airway (LMA-Fastrach) in patients with difficult airways. Anaesth Intensive Care 1998;26(4):387-391.

58. Kapila A, Addy EV, Verghese C, Brain AI. The intubating laryngeal mask airway: an initial assessment of performance. $\mathrm{Br} \mathrm{J}$ Anaesth 1997;79(6):710-713.

59. Kihara S, Watanabe S, Brimacombe J, Taguchi N, Yaguchi Y, Yamasaki Y. Segmental cervical spine movement with the intubating laryngeal mask during manual in-line stabilization in patients with cervical pathology undergoing cervical spine surgery. Anesth Analg 2000;91(1):195-200.

60. Nakazawa K, Tanaka N, Ishikawa S, Ohmi S, Ueki M, Saitoh Y, et al. Using the intubating laryngeal mask airway (LMA-Fastrach) for blind endotracheal intubation in patients undergoing cervical spine operation. Anesth Analg 1999;89(5):1319-1321.

61. Shung J, Avidan MS, Ing R, Klein DC, Pott L. Awake intubation of the difficult airway with the intubating laryngeal mask airway. Anaesthesia 1998;53(7):645-649.

62. Cone DC. Compression-only CPR: pushing the science forward. JAMA 2010;304(13):1493-1495.

63. Iwami T, Kitamura T, Kawamura T, Mitamura H, Nagao K, Takayama $\mathrm{M}$, et al. Chest compression-only cardiopulmonary resuscitation for out-of-hospital cardiac arrest with public-access defibril- lation: a nationwide cohort study. Circulation 2012;126(24):28442851.

64. Berg RA, Sanders AB, Kern KB, Hilwig RW, Heidenreich JW, Porter ME, Ewy GA. Adverse hemodynamic effects of interrupting chest compressions for rescue breathing during cardiopulmonary resuscitation for ventricular fibrillation cardiac arrest. Circulation 2001; 104(20):2465-2470.

65. Wang HE, Simeone SJ, Weaver MD, Callaway CW. Interruptions in cardiopulmonary resuscitation from paramedic endotracheal intubation. Ann Emerg Med 2009;54(5):645.e1-652.e1.

66. Martin LD, Mhyre JM, Shanks AM, Tremper KK, Kheterpal S. 3,423 emergency tracheal intubations at a university hospital: airway outcomes and complications. Anesthesiology 2011;114(1):42-48.

67. Benger JR, Voss S, Coates D, Greenwood R, Nolan J, Rawstorne S, et al. Randomised comparison of the effectiveness of the laryngeal mask airway supreme, i-gel and current practice in the initial airway management of prehospital cardiac arrest (REVIVE-Airways): a feasibility study research protocol. BMJ Open 2013;3(2)e002467.

68. Morrison LJ, Deakin CD, Morley PT, Callaway CW, Kerber RE, Kronick SL, et al. Part 8: Advanced life support: 2010 International Consensus on Cardiopulmonary Resuscitation and Emergency Cardiovascular Care Science With Treatment Recommendations. Circulation 2010;122(16 Suppl 2):S345-S421.

69. Cook TM, Hommers C. New airways for resuscitation? Resuscitation 2006;69(3):371-387.

70. Giugni A, Cavallo P, Giuntoli L, Coniglio C. Laryngeal tube as airway rescue device from prehospital tracheostomy: a case report. Minerva Anestesiol 2012;78(6):725-728.

71. Heuer JF, Barwing J, Eich C, Quintel M, Crozier TA, Roessler M. Initial ventilation through laryngeal tube instead of face mask in out-of-hospital cardiopulmonary arrest is effective and safe. Eur J Emerg Med 2010;17(1):10-15.

72. Hubble MW, Wilfong DA, Brown LH, Hertelendy A, Benner RW. A meta-analysis of prehospital airway control techniques part II: alternative airway devices and cricothyrotomy success rates. Prehosp Emerg Care 2010;14(4):515-530.

73. Schalk R, Meininger D, Ruesseler M, Oberndorfer D, Walcher F, Zacharowski K, et al. Emergency airway management in trauma patients using laryngeal tube suction. Prehosp Emerg Care 2011; 15(3):347-350.

74. Kılıç T, Goksu E, Durmaz D, Yıldız G. Upper cervical spine movement during intubation with different airway devices. Am J Emerg Med 2013;31(7):1034-1036.

75. Asai T, Shingu K. Use of the laryngeal mask during emergence from anesthesia in a patient with an unstable neck. Anesth Analg 1999; 88(2):469-470.

76. Asai T, Shingu K. Use of the laryngeal tube during emergence from anaesthesia in a patient with an unstable neck. Anaesthesia 2004; 59(3):300-301.

77. Dob DP, Shannon CN, Bailey PM. Efficacy and safety of the laryngeal mask airway vs Guedel airway following tracheal extubation. Can J Anaesth 1999;46(2):179-181.

78. Koga K, Asai T, Vaughan RS, Latto IP. Respiratory complications associated with tracheal extubation. Timing of tracheal extubation and use of the laryngeal mask during emergence from anaesthesia. Anaesthesia 1998;53(6):540-544.

79. McHardy FE, Chung F. Postoperative sore throat: cause, prevention and treatment. Anaesthesia 1999;54(5):444-453.

80. Rieger A, Brunne B, Hass I, Brummer G, Spies C, Striebel HW, Eyrich K. Laryngo-pharyngeal complaints following laryngeal mask airway and endotracheal intubation. J Clin Anesth 1997;9(1):42-47.

81. Brimacombe J, Berry A. Laryngeal mask airway cuff pressure and position during anaesthesia lasting one to two hours. Can J Anaesth 1994;41(7):589-593. 


\section{Supraglottic Airway Devices}

82. Brimacombe J, Holyoake L, Keller C, Barry J, Mecklem D, Blinco A, Weidmann K. Emergence characteristics and postoperative laryngopharyngeal morbidity with the laryngeal mask airway: a comparison of high versus low initial cuff volume. Anaesthesia 2000;55(4): 338-343.

83. Brimacombe J, Holyoake L, Keller C, Brimacombe N, Scully M, Barry J, et al. Pharyngolaryngeal, neck, and jaw discomfort after anesthesia with the face mask and laryngeal mask airway at high and low cuff volumes in males and females. Anesthesiology 2000;93(1): 26-31.

84. Grady DM, McHardy F, Wong J, Jin F, Tong D, Chung F. Pharyngolaryngeal morbidity with the laryngeal mask airway in spontaneously breathing patients: does size matter? Anesthesiology 2001; 94(5):760-766.

85. Ouellette RG. The effect of nitrous oxide on laryngeal mask cuff pressure. AANA J 2000;68(5):411-414.

86. Lloyd Jones FR, Hegab A. Case report. Recurrent laryngeal nerve palsy after laryngeal mask airway insertion. Anaesthesia 1996;51(2): 171-172.

87. Figueredo E, Vivar-Diago M, Muñoz-Blanco F. Laryngo-pharyngeal complaints after use of the laryngeal mask airway. Can J Anaesth 1999;46(3):220-225.

88. Inomata $\mathrm{S}$, Nishikawa $\mathrm{T}$, Suga $\mathrm{A}$, Yamashita $\mathrm{S}$. Transient bilateral vocal cord paralysis after insertion of a laryngeal mask airway. Anesthesiology 1995;82(3):787-788.

89. Haris ZM, Loo WT, Brimacombe J. Frenular injury during insertion of the ProSeal laryngeal mask airway using the introducer tool technique. Anesth Analg 2006;102(6):1906-1907.

90. Barker P, Langton JA, Murphy PJ, Rowbotham DJ. Regurgitation of gastric contents during general anaesthesia using the laryngeal mask airway. Br J Anaesth 1992;69(3):314-315.
91. Keller C, Brimacombe J, Bittersohl J, Lirk P, von Goedecke A. Aspiration and the laryngeal mask airway: three cases and a review of the literature. Br J Anaesth 2004;93(4):579-582.

92. Rabey PG, Murphy PJ, Langton JA, Barker P, Rowbotham DJ. Effect of the laryngeal mask airway on lower oesophageal sphincter pressure in patients during general anaesthesia. Br J Anaesth 1992; 69(4):346-348

93. Brimacombe JR, Berry A. The incidence of aspiration associated with the laryngeal mask airway: a meta-analysis of published literature. J Clin Anesth 1995;7(4):297-305.

94. Verghese C, Brimacombe JR. Survey of laryngeal mask airway usage in 11,910 patients: safety and efficacy for conventional and nonconventional usage. Anesth Analg 1996;82(1):129-133.

95. Ramachandran SK, Mathis MR, Tremper KK, Shanks AM, Kheterpal S. Predictors and clinical outcomes from failed Laryngeal Mask Airway Unique: a study of 15,795 patients. Anesthesiology 2012; 116(6):1217-1226

96. Bernardini A, Natalini G. Risk of pulmonary aspiration with laryngeal mask airway and tracheal tube: analysis on 65,712 procedures with positive pressure ventilation. Anaesthesia 2009;64(12):1289-1294.

97. Schmidbauer W, Bercker S, Volk T, Bogusch G, Mager G, Kerner T. Oesophageal seal of the novel supralaryngeal airway device I-Gel in comparison with the laryngeal mask airways Classic and ProSeal using a cadaver model. Br J Anaesth 2009;102(1):135-139.

98. Keller C, Brimacombe J, Rädler C, Pühringer F. Do laryngeal mask airway devices attenuate liquid flow between the esophagus and pharynx? A randomized, controlled cadaver study. Anesth Analg 1999;88(4):904-907.

99. Schmidbauer W, Genzwürker H, Ahlers O, Proquitte H, Kerner T. Cadaver study of oesophageal insufflation with supraglottic airway devices during positive pressure ventilation in an obstructed airway. Br J Anaesth 2012;109(3):454-458.

\section{Discussion}

Berkow: I have a comment and a question. I agree that it definitely revolutionized failed mask ventilation and failed intubation. We just have to remember that if the obstruction is at the level of the glottis, an SAD [supraglottic airway device] is not going to help. It doesn't work for every patient you can't intubate. I also wanted to ask if you would comment on the use of SADs for prone cases as well as laparoscopic procedures. Especially in the United Kingdom, they're a lot more adventurous with SADs than we are here in the United States. I'm still a little nervous putting them in a prone patient or obese patient for laparoscopic surgery, but I know that it's being done.

Ramachandran: For prone patients, in our database, I was surprised to find we had 71 instances where an LMA [laryngeal mask airway] had been placed in a prone patient. And I want to bet that all the anesthesiologists in those cases were visiting instructors from England. We actually did not find a positional difference in failure rates. But I think if you had a situation where you lost the airway, you wouldn't have a leg to stand on in this country. In England, perhaps the obesity rates are a little bit lower, and perhaps there's less scrutiny of the techniques. But I really don't see the advantage in that situation of avoiding the ETT. I think "you can do it and therefore do it" isn't a great scientifically valid way of using the LMA. For laparoscopic procedures, I certainly would not recommend its use. The people who use it in England say that it's particularly useful because it reduces the amount of muscle relaxant they have to give; it's a big package deal; and they find the patients have less pain, there are earlier wakeups, they're more comfortable in recovery. But I've been there as well when the LMA fails; in those cases, it's not very pretty at all. We talked about environment a little bit earlier today. In America, if I call for help, there's always somebody to come to my OR [operating room] in the next minute, and it's usually an anesthesiologist. In England, I may be the only person in the OR suite for that afternoon. So it's not a very good method, in my opinion, to place these for laparoscopic surgeries. The profile that's been described suggests that, in their hands and their technique, it's OK. I wouldn't recommend it for here, though.

Durbin: Using an LMA in the prone position electively a few times allows enough experience and skill, so that if it's necessary in an emergency situa- 
tion, it can be done without hesitation. If you have a patient prone with one of those face protection systems and the ETT becomes dislodged, insertion of an LMA prone is much more difficult if not impossible. But if you can turn the patient's head to the side, an LMA can easily be inserted and works really nicely. I actually encourage our residents to do prone face mask ventilation because I think that's the gold standard rescue technique, but I think the LMA has made prone manual ventilation a lot easier. I agree with Krish [Ramachandran]: I wouldn't recommend elective use of an LMA for laparoscopic procedures in this country. There's no benefit in this use and possibly some risk. I use an LMA as a conduit for the fiberoptic bronchoscope during PDTs [percutaneous dilational tracheostomies]. That's my standard procedure. I like one of those mentioned because it allows the RTs [respiratory therapists] to easily place it, rarely fails for ventilation, and usually provides a very good view of the larynx. The RTs drive the bronchoscope, and I rarely have to help them enter the larynx through the LMA. While I'm preparing for the procedure, the RTs just go ahead and place, confirm, and use the LMA with the bronchoscope; it's extremely easy. The original LMA with the crossbars was not easy to use with the scope, but some of the newer innovations are really quite useful for this purpose.

Collins: In regard to practice patterns in the United Kingdom, I'm struck by such practice variability in the United States. I'll give 2 examples. The first is a type of case such as in ophthalmology when the patient is often turned $180^{\circ}$, and the anesthesiologist is at the patient's feet during the procedure. Another similar example is a lithotripsy case where a patient is somewhat at a distance from the anesthesiologist and submerged partially in water. There is extreme variability in airway management preferences for such cases in what seems to come down to the clinician's comfort level and patient selection given predictors for ease of mask ventilation or intubation.

\section{Ramachandran: I agree.}

Hurford: As far as other uses, we use the i-gel as our conduit of choice for all of our interventional bronchoscope procedures. Also, for a lot of upper airway surgery, you get a lot of visualization of the upper airway that you'd bypass with the ETT, so with some pathologies, the surgeons are actually requesting it. The other neat niche that we amazingly use is we do a lot of pediatric burns, and the kids come back and require multiple operations. ${ }^{1}$ Most of our pediatric burns, including prone position, are done with the LMA. One insertion technique you didn't mention that we use with the i-gel, which avoids fingers in the mouth, is to use a tongue depressor and press down, and once the airway is seated, do a jaw lift. The other question I had is can you give us any specific guidelines for mechanical ventilation with SADs? What is your practice?

Ramachandran: My personal practice is to have a very small amount of PEEP and low $\mathrm{V}_{\mathrm{T}}$ [tidal volume]. So, for a typical adult patient, I would set about 4-5 cm PEEP and 400-450 $\mathrm{mL}$ of $\mathrm{V}_{\mathrm{T}}$ to achieve a pressure of $<18 \mathrm{~cm} \mathrm{H}_{2} \mathrm{O}$. Even with the secondgeneration devices, where the big advantage is that pharyngeal leak pressures are much higher, 25-30 $\mathrm{cm} \mathrm{H}_{2} \mathrm{O}$, compared to the first-generation devices, which were $18-20 \mathrm{~cm} \mathrm{H}_{2} \mathrm{O}$. So, you're more likely to have success with second-generation devices for procedures like laparoscopy in obese patients. The 2 things which matter with positivepressure ventilation through LMA are: how good is your lung compliance, and how good is your seal? If you test your seal pressure before you start somebody on positive-pressure ventilation and if you're having a leak at $15-18 \mathrm{~cm} \mathrm{H}_{2} \mathrm{O}$, you're unlikely to have success with positive-pressure ventilation in that patient with the SAD in that position. So PEEP might help with compliance of the lung and make ventilation easier. The second thing to consider is depth of anesthesia; it's a supraglottic airway, so any change in compliance that you see for positivepressure ventilation, the first sign of laryngospasm, is often a change in $\mathrm{V}_{\mathrm{T}}$. So if you set up pressure control, you first see a change in $\mathrm{V}_{\mathrm{T}}$ as you're beginning to have a dynamic laryngospasm develop. These are tips and tricks, but the most important thing is to just make sure you've done a lot of these and do them well. The key thing is to have the technique of anesthesia and the technique of management of the SAD. Both are key to the success of use of these devices with positive-pressure ventilation.

Hurford: Do you have a preference for the use of neuromuscular blockade?

Ramachandran: I've personally used it on 3 continents, so I'm comfortable with the use of muscle relaxants with LMAs. It's my experience that if you hit the right anesthetic depth, there's no need for muscle relaxants, and you can continue to ventilate a patient even without muscle relaxants with an SAD. The depth of anesthesia is very important.

Berkow: One additional indication for SADs you didn't mention: the recent Difficult Airway Society guidelines for extubation ${ }^{2}$ recommend an SAD as a bridge to extubation, either replacing the ETT with an LMA or passing it behind the ETT itself. That's also another use I wanted to mention.

\section{REFERENCES}

1. McCall JE, Fischer CG, Schomaker E, Young JM. Laryngeal mask airway use in children with acute burns: intraoperative airway management. Paediatr Anaesth 1999;9(6):515-520.

2. Difficult Airway Society Extubation Guidelines Group, Popat M, Mitchell V, Dravid R, Patel A, Swampillai C, Higgs A. Difficult Airway Society guidelines for the management of tracheal extubation. Anaesthesia 2012;67(3):318-340. 